\title{
Scheme for pharmacists to give oral health advice rolls outs
}

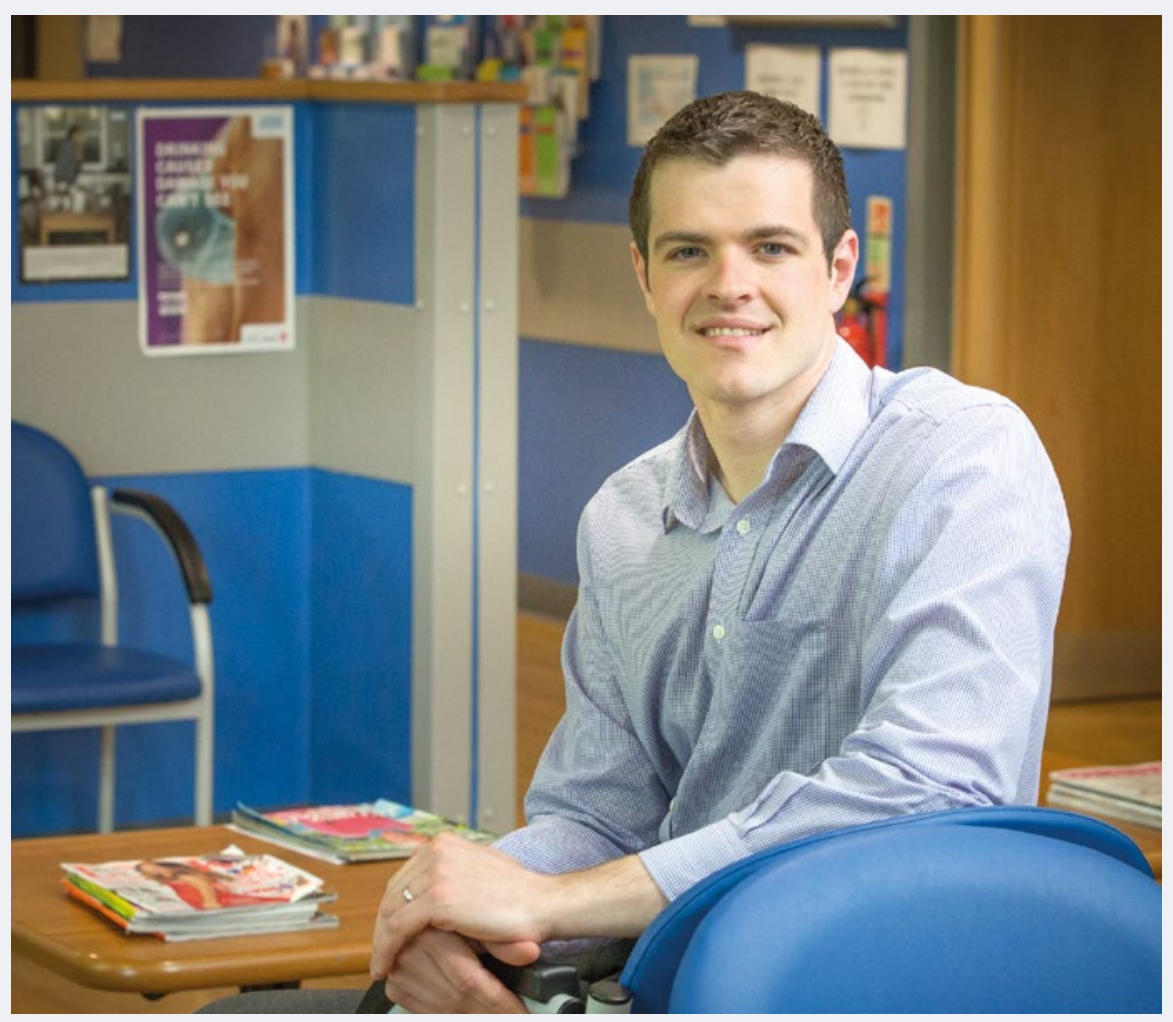

Andrew Sturrock, Principal Lecturer and Programme Leader for the Master of Pharmacy programme in the School of Pharmacy and Pharmaceutical Sciences at the University of Sunderland

A pilot scheme designed to improve oral health by pharmacists giving advice is being rolled out across the North East to try and save the NHS money.

A project between the University of Sunderland and the Public Health Team at Durham County Council is using the accessibility of community pharmacies that are often visited by patients to offer a venue in which pharmacists can deliver oral health advice and information.

Currently, poor oral health is estimated to cost the NHS in England $£ 3.4$ billion annually and tooth decay is the most common reason for hospital admissions among children aged five to nine.

A pilot - detailed in research published in the $B D J$ in $2017^{1}$ - was carried out in 2016 at five pharmacies in deprived areas of County Durham.

It involved a five-minute oral health intervention to patients as they waited for prescriptions or when they had come in for advice and medications.
In all, 1,089 patients took part in the intervention, which included advising patients on how to brush their teeth properly, checking they were using the right products and providing key information on how to look after teeth and gums.

Results from evaluation questionnaires showed that $72 \%$ of participants reported that their knowledge of oral health was much better, $66 \%$ said they would make changes to their oral health habits, and $64 \%$ thought a pharmacy was the right place to receive oral health advice.

The study concluded that a community pharmacy was seen by patients as an acceptable provider of oral health interventions and had the potential to provide positive changes to the oral health of the population.

Andrew Sturrock, Principal Lecturer and Programme Leader for the Master of Pharmacy programme in the School of Pharmacy and Pharmaceutical Sciences at the University of Sunderland, worked with
Durham County Council's Public Health team to develop the project based on his previous research assessing the impact of community pharmacies.

Mr Sturrock said: 'This started as a simple idea, based on my research looking at the role of community pharmacies, who are well-trained healthcare professionals, easily accessible and frequently visited by patients, and required to provide healthy living advice to patients - therefore offering a little explored avenue for the delivery of oral health interventions.

'We already know there are lots of people who don't have a dentist, have phobias about dental treatment or avoid regular check-ups, especially in deprived areas. The pharmacy is certainly not taking over the dentists' role - this is just about giving some really basic healthcare advice and signposting patients in the right direction.

'It's also about trying to prevent people from needing dental treatment later on, potentially saving millions on NHS treatment.'

The scheme has now been rolled out across Tyneside, Teesside, County Durham and Carlisle.

Claire Jones, Public Health Pharmacy Adviser at Durham County Council said: 'The success of this scheme did help to keep oral health training on the agenda for community pharmacies through regional pharmacy training sessions that were subsequently run by the regional oral health team at Health Education England in 2018.

'In addition, oral health became one of the local targets for HLPs [healthy living pharmacy] in County Durham and oral health in children is now a focus in the current national quality payment scheme for pharmacies.'

\section{References}

1. Sturrock A, Cussons $H$, Jones $C$, Woodcock $C$ and Bird L. Oral health promotion in the community pharmacy: an evaluation of a pilot oral health promotion intervention. Br Dent J 2017; 223: 521-525. 